\title{
MIGUEL DEL PRADO, PINTOR DE RETABLOS EN VALENCIA. SU FALLECIMIENTO EN LAS GERMANÍAS (1521)*
}

\author{
MERCEDES GómEZ-FerReR ${ }^{1}$ \\ Universitat de València
}

\begin{abstract}
Miguel del Prado, pintor que realizó una compañía con Miguel Esteve para pintar la desaparecida capilla de la casa de la ciudad de Valencia en 1519 es un autor del que se tienen muy pocas noticias. Su personalidad, identificada durante un tiempo con el Maestro del Grifo, ha sido recientemente cuestionada. En el presente texto damos a conocer un contrato para el retablo de la capilla del Rosario del convento de Santo Domingo de Valencia que no pudo concluir por su temprano fallecimiento. Certificamos que éste se produjo en la revuelta de las Germanías en la Batalla de Almenara de 1521, rebajando en más de 16 años su cronología ya que se creía fallecido en 1537.
\end{abstract}

Palabras clave: Miguel del Prado; pintura renacentista valenciana; Miguel Esteve; Germanías; retablo del Rosario.

MIGUEL DEL PRADO, RETABLE PAINTER IN VALENCIA. HIS DEATH IN THE GERMANÍAS REVOLT (1521)

Miguel del Prado, a painter who formed a company with Miguel Esteve in order to paint the now-lost Valencia town hall chapel in 1519, is an artist for whom there is scant documentary evidence. He has been identified with the anonymous Master of the Grifo, but this has been questioned recently. The author here offers news of a contract given to del Prado for an altarpiece in the Rosary Chapel of the old convent of Santo Domingo in Valencia that he was unable to fulfill due to his untimely death. It has been possible to certify that he perished on the battlefield of Almenara during the Germanías Revolt of 1521. Therefore the chronology for this painter has now been reduced by more than 16 years, because he was thought to have died in 1537.

Key words: Miguel del Prado; Valencian Renaissance painting; Miguel Esteve; Germanías Revolt; Rosario retable.

Cómo citar este artículo / Citation: Gómez-Ferrer, Mercedes (2017): "Miguel del Prado, pintor de retablos en Valencia. Su fallecimiento en las Germanías (1521)". En: Archivo Español de Arte, vol. 90, núm. 358, Madrid, pp. 125-140. doi: 10.3989/aearte.2017.08

\section{Introducción}

A pesar de los numerosos estudios publicados en los últimos años, el análisis sobre la pintura en Valencia durante la primera mitad del siglo XVI sigue pendiente de poder resolver importantes incógnitas. En un período en el que destacan figuras de primer orden como Pablo de San Leocadio en la transición del siglo y sobre todo, los Hernandos a partir de 1506, otros

* Este trabajo se ha realizado en el marco del proyecto (HAR2014-54751-P) "Ecos culturales artísticos y arquitectónicos entre Valencia y el Mediterráneo en época Moderna" financiado por el Ministerio de Economía y Competitividad.

1 mercedes.gomez-ferrer@uv.es / ORCID iD: http://orcid.org/0000-0003-4752-3979. 
muchos han quedado eclipsados por su menor calidad y por su dependencia con respecto a estos grandes nombres. Se han ido esclareciendo algunas personalidades como la del pintor Nicolás Falcó y miembros de esta familia, su hijo Onofre y su nieto Nicolás ${ }^{2}$. Se han identificado algunos anónimos como Franci Joan, pintor de San Narciso ${ }^{3}$. Otros muchos siguen resultando problemáticos como los miembros de la familia Cabanes, Pere Cabanes, padre, sus hijos Martí, Juan y Pere, y su posible hermano Antonio Cabanes ${ }^{4}$. Su individualidad, a pesar de algunas propuestas, no ha podido ser esclarecida con seguridad ni relacionada de forma directa con anónimos de la pintura valenciana como el Maestro de Artés o el Maestro de Borbotó ${ }^{\text {. }}$ Por otro lado, otros, a pesar de seguir permaneciendo en el anonimato, van configurando un corpus más o menos coherente como el Maestro de Perea ${ }^{6}$ o el más avanzado Maestro de Alzira. Las dificultades además aumentan si tenemos en cuenta que en muchos de los casos no es posible definir una única personalidad porque los talleres funcionan como asociaciones de pintores, ya sea de forma familiar o por la formación de compañías. Ya hemos mencionado el taller de los Cabanes, pero otros iniciados en la centuria anterior, como el taller de los Osona, encabezado por Rodrigo de Osona, acompañado por sus hijos, Francisco y Jerónimo, siguen planteando dudas? Es más, muchas veces se producían asociaciones entre pintores de distintos talleres y son varios los retablos que Rodrigo de Osona y Pere Cabanes contratan juntos, por lo que aún se complica más la situación ${ }^{8}$.

También se prolongó en el tiempo el taller del propio Pablo de San Leocadio que continuaron sus hijos Miguel Joan y Felipe Pablo, aunque la personalidad de este último se encuentra más definida por la conservación de obra claramente documentada ${ }^{9}$. Otras familias como los Macip, Vicente y Joan, han ocasionado ríos de tinta, pero la delimitación actual parece ya comúnmente aceptada. A esta problemática de los talleres familiares, se añade la cuestión de las compañías de pintores, que fueron muy habituales en el medio valenciano desde el último cuarto del siglo XV. Algunas han quedado bastante determinadas por las obras en solitario realizadas por sus miembros como los anteriormente citados, Pablo de San Leocadio ${ }^{10}$ y su compañero Francesco Pagano, o los propios Hernandos, Yáñez y Llanos ${ }^{11}$. Sin embargo, hay otras que siguen siendo muy dudosas ante la imposibilidad de identificar la obra independiente de sus miembros. Entre éstas se sitúa la de los pintores Miguel Esteve y Miguel del Prado, compañía formada en el primer cuarto del siglo XVI en Valencia con pintura en la órbita de Pablo de San Leocadio y evidentes deudas de los Hernandos. Ante la nueva documentación localizada vamos a tratar de ofrecer algo de luz al respecto de estos pintores.

\footnotetext{
2 Gómez-Ferrer, 2011-12: 77-94.

3 Gómez-Ferrer/Corbalán de Celis, 2014: 75-92.

${ }^{4}$ Framis, 2006: 149-210. Gómez-Ferrer, 2011-12: 77-94. La determinación de las relaciones de los miembros de la familia Cabanes ha sido muy problemática. Hasta ahora se tenía claro que el cabeza del taller era Pere Cabanes I quien tenía un hijo del mismo nombre, Pere Cabanes II y otro hijo de nombre Juan, que muere en 1508. Por documentación inédita podemos afirmar que Martí Cabanes a quien se tenía por hermano de Pere Cabanes I, es en realidad hijo suyo. Archivo de Protocolos del Patriarca de Valencia (APPV), notario: Francesc Hieronim Peres, signatura: 15445, 2 de enero de 1520, donación inter vivos entre Pere Cabanes y su hijo Martí Cabanes de los bienes que aquel tenía en su casa de la calle San Vicente, parroquia de San Martín. Antoni Cabanes por ahora se sigue considerando hermano de Pere Cabanes I, sin que se haya podido confirmar la relación exacta.

5 Benito/Gómez Frechina, 2006: 148-169; 2009.

${ }^{6}$ Gómez Frechina, 2012.

7 Samper/Azorín, 2006: 133-148.

${ }^{8}$ Rodrigo de Osona y Pere Cabanes aparecen asociados en diversos contratos de pintura como el retablo para el convento de San Francisco o el de San Agustín. Sanchis Sivera, 1930-31: 70-71.

${ }_{9}$ Claramente identificado a partir del retablo de Santo Domingo del monasterio de Santo Domingo de Valencia hoy en el Museo de Bellas Artes, concertado con Felipe Pablo de San Leocadio en el año 1525.

10 Company, 2006.

11 Gómez Frechina, 2011.
} 


\section{Miguel Esteve y Miguel del Prado, compañía de pintores}

La entrada en escena de esta compañía de pintores en la Valencia del primer cuarto del siglo XVI se produce con la solicitud de colaboración que hizo Miguel Esteve a Miguel del Prado para poder hacer frente al contrato firmado inicialmente por el primero con los consellers de la casa de la ciudad para pintar la capilla que se acababa de remodelar ${ }^{12}$. La obra había sido contratada el 18 de septiembre de 1518 exclusivamente con Miguel Esteve, pero éste, que se había comprometido a acabarla en escasos tres meses, solicitaba, pasado el plazo previsto, en abril de 1519, la colaboración de otro pintor, Miguel del Prado para poder hacer frente a todo el conjunto. Los sucesivos pagos por el trabajo de ambos se terminan en mayo de 1520, con lo que podemos dar por finalizado el encargo.

La capilla fue derribada junto con el resto del edificio en 1860, sin embargo, algunas de las pinturas fueron arrancadas y salvadas en parte. El programa encargado a Miguel Esteve era una pintura que debía seguir de cerca el modelo de los frescos del presbiterio catedralicio, terminado por Pagano y Leocadio, unos años antes. La bóveda tenía en los plementos entre los nervios cruceros unos ángeles músicos, similares a los de la catedral y en las pequeñas esquinas que formaban los terceletes unos ángeles con instrumentos de la pasión. Del conjunto de todos estos ángeles de las bóvedas no se ha conservado ningún resto. En los lunetos de los muros estaban pintados los doce apóstoles sentados en bancos con un libro en la mano y las insignias de sus martirios, rodeando un Cristo en Majestad, siguiendo también el precedente catedralicio, que en parte sí se han conservado. La técnica era diferente pues no se realizaba al fresco sino con pintura al óleo tras tres manos de enyesado de la superficie. En la actualidad se conservan un total de ocho lunetos repartidos entre el Museo Histórico Municipal y el Museo de la ciudad. Los cuatro primeros se corresponden con San Andrés, San Pablo, Santiago el Mayor (fig. 1) y San Bartolomé y San Mateo, compartiendo luneto. Y en el segundo museo se encuentra San Juan (fig. 2), San Pedro (fig. 3), y dos lunetos más trasladados a lienzo en peor estado, uno con San Felipe y otro con Santiago el Menor y San Judas Tadeo. También se conservan un fragmento de un Ángel custodio, quizá uno de los querubines que rodeaba la Majestad y una cabeza de la Virgen, no mencionada en el contrato y con numerosos repintes, presumiblemente posterior y ajena a este encargo.

Sin posibilidad ninguna de confirmación, desde que Tramoyeres proporcionara las noticias documentales, se venían atribuyendo algunos lunetos a Miguel Esteve y otros a Miguel del Prado. El propio Tramoyeres decía que de forma provisional pertenecían a Esteve el San Jaime, San Pedro, San Pablo ${ }^{13}$, San Bartolomé y San Mateo y los citados ángel ${ }^{14}$ y cabeza de la Virgen; y a Miguel del Prado el San Juan evangelista, y los dos lunetos en peor estado de conservación. A partir de entonces estas atribuciones se habían perpetuado y con posterioridad se había tratado de individualizar, la obra de uno y de otro.

\section{Miguel Esteve y Miguel del Prado, propuestas de individualización}

El punto de partida para el análisis de estos pintores procedía, como hemos señalado, de las hipótesis de Tramoyeres de adjudicación de determinados lunetos de la antigua capilla de los jurados y de la configuración de un corpus pictórico en razón de las similitudes formales. A Miguel Esteve, que se consideraba el pintor principal y con más calidad, se le atribuían entre otras, La Sagrada Familia (fig. 4), procedente de Santo Domingo, hoy en el Museo de Bellas

12 Tramoyeres, 1919: 74-100.

13 Tramoyeres, 1919. San Pablo no se menciona en el texto, sin embargo, aparece en la fotografía de la p. 84.

14 Tramoyeres, 1919. El ángel se dice que es de Miguel Esteve, pero en el pie de foto de la p. 88 se atribuye a Miguel del Prado con interrogante. 


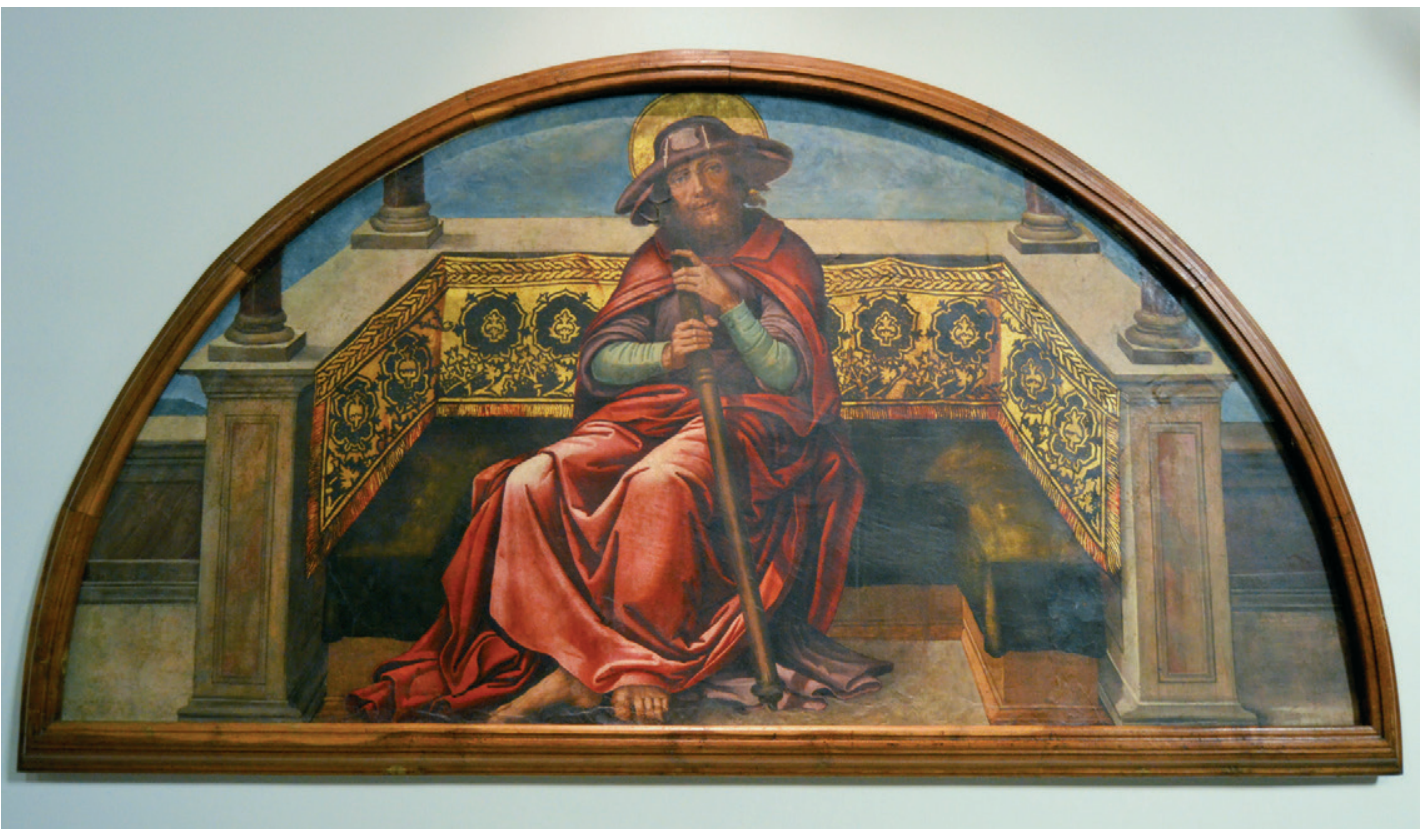

Fig.1. San Jaime, Miguel Esteve y Miguel del Prado, 1519. Luneto de la antigua casa de la ciudad de Valencia. Museo Histórico Municipal de Valencia.

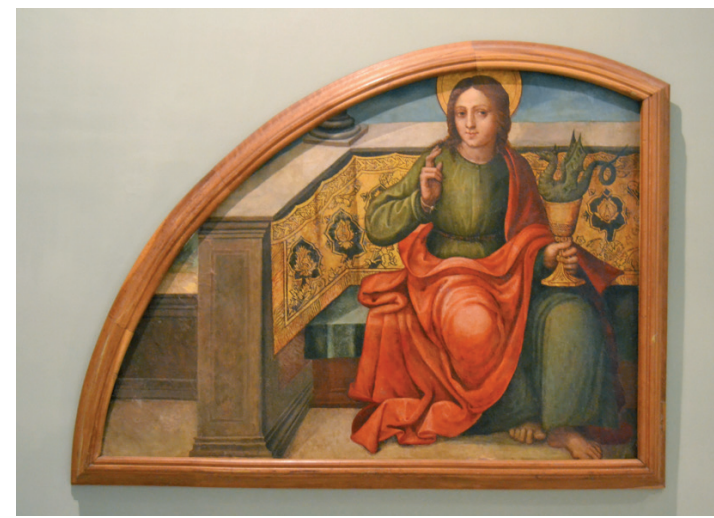

Fig. 2. San Juan, Miguel Esteve y Miguel del Prado, 1519. Luneto de la antigua casa de la ciudad de Valencia. Museo Histórico Municipal de Valencia.

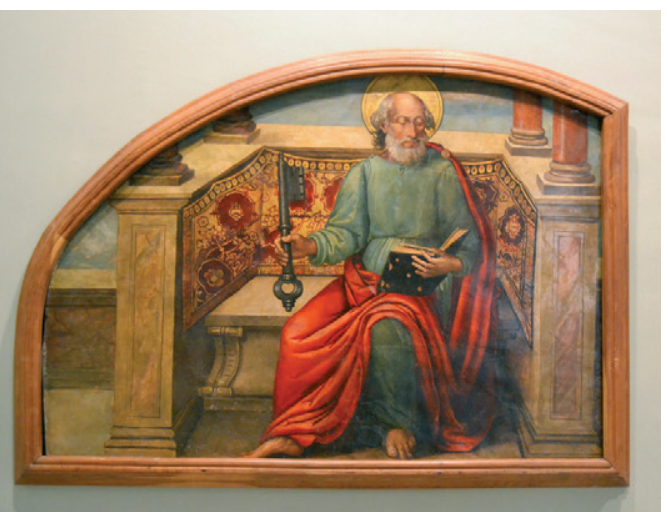

Fig. 3. San Pedro, Miguel Esteve y Miguel del Prado, 1519. Luneto de la antigua casa de la ciudad de Valencia. Museo Histórico Municipal de Valencia.

Artes de Valencia ${ }^{15}$, el gran San Miguel de este museo, que procedía de Montesa ${ }^{16}$, las tablas de la Resurrección y la Anunciación del mismo Museo ${ }^{17}$, un Pentecostés de la colección Lacuadra ${ }^{18}$,

15 Post, 1953: 319-320. Catalá, 1994: 208-211.

16 Post, 1953: 322-324, indica que procede del claustro del castillo de Montesa según le ha hecho saber Saralegui, a partir de aquí, los autores repiten este dato. Benito: 2006, 228-229.

17 Post, 1953: 319-323. Saralegui, 1954: 190.

18 Saralegui, 1945: 21. Post, 1953: 331, la considera obra dudosa de Miguel Esteve y en Samper: 2013, 107 de Miguel del Prado. 
y una Ascensión de colección particular ${ }^{19}$, la tabla de Dimas y el donante de la catedral $^{20}$, la Virgen del Caballero de Colonia del Colegio del Corpus Christi21, el retablo de San Antonio Abad en Lucena del $\mathrm{Cid}^{22}$ y la tabla de la duda de San José de la Jana $^{23}$, como obras más destacadas de su producción ${ }^{24}$.

Este pintor contaba además con una serie de noticias documentales que venían a reforzar su personalidad. Irrumpía en la escena valenciana como pintor de retablos testificando a favor de los Forment en el pleito que tuvieron en 1510 sobre el retablo contratado por el gremio de plateros de la ciudad de Valencia que iba a ser pintado por los Hernandos, con lo cual se le vinculaba en cierta medida con estos pintores ${ }^{25}$. Se había incluso especulado con la posibilidad de que hubiera colaborado con ellos en las tablas de las puertas del retablo mayor de la catedral valenciana, sin que esta noticia se pueda confirmar documentalmente $^{26}$. Por otro lado, se conocían algunos contratos para la realización de retablos significativos, fundamentalmente el de Don Alonso de Aragón, obispo de Tortosa en 1511 para lugar y con iconografía des-

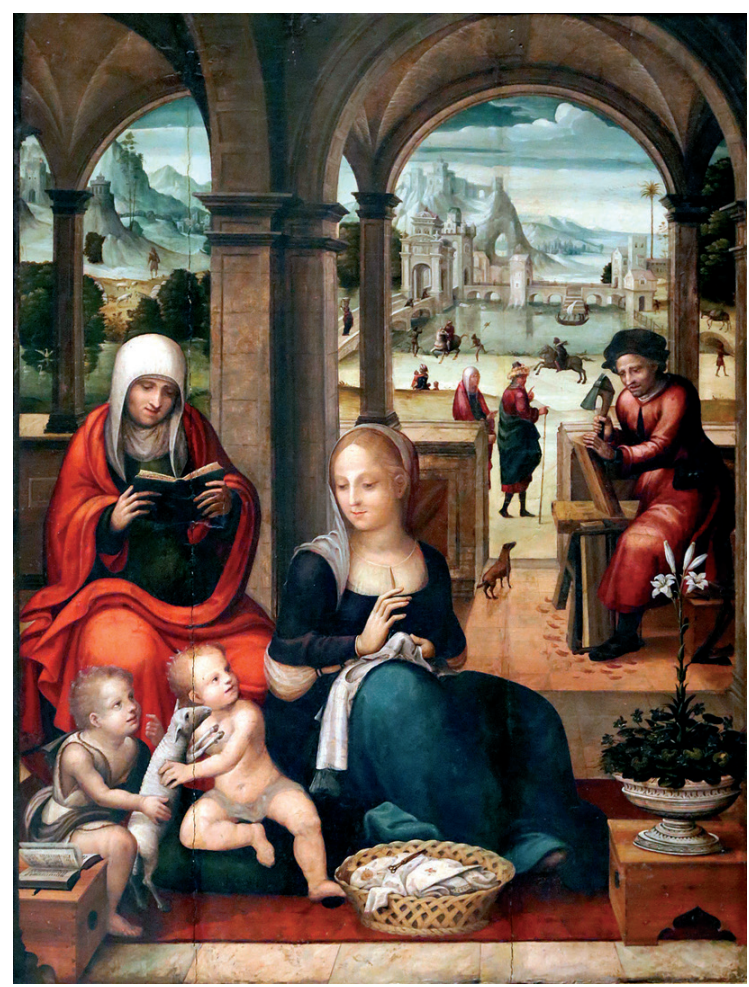

Fig. 4. Sagrada Familia en el taller de San José, Miguel Esteve, Museo de Bellas Artes de Valencia. conocida ${ }^{27}$ y el gran retablo para la Valldigna con el tema de los gozos de la Virgen concertado el 17 de julio de $1519^{28}$, que el pintor Franci Joan (maestro de San Narciso) no había podido realizar por su fallecimiento prematuro ${ }^{29}$ y que fue encargado a Esteve. Miguel Esteve también se mencionaba en varios documentos firmados en Valencia junto a otros pintores, como el de diciembre de 1520 en el que figura como síndico cuando se plantea la realización de un colegio de pintores y los de 1521 junto a una serie de pintores en la ciudad, reunidos y dispuestos a combatir en las Germanías ${ }^{30}$. Su nombre estaba en las listas de pago de impuestos o tacha real de 1510 habitando en la parroquia de San Martín como muchos otros pintores. El 20 de

19 López/Samper, 2006: 146; sin embargo en Samper, 2013: 107 se considera del corpus tradicionalmente atribuido a Miguel del Prado.

20 Soler d'Hyver, 1999: 438-439 propone su atribución a Miguel Esteve.

21 Tormo, 1932: 47. Post, 1953: 312-315.

22 Post, 1953: 312-313.

${ }_{23}$ Post, 1953: 317-318. Marco, 2013: 486-487.

24 Post, 1953: 325 añadía también una Virgen con el niño de la colección Tolrá, una Adoración de los pastores de la Cluett collection, Georgia (USA), y un panel de Santiago de la iglesia de San Bartolomé que estuvo en el Museo diocesano hasta 1936, con alguna duda sobre la atribución exacta.

25 Salas, 1943: 75. La declaración de Miguel Esteve pintor de retablos es de 12 de julio de 1510.

26 Tramoyeres, 1919: 92. Catalá, 1981: 42. Company, 1987: 44 y 49.

27 Gómez-Ferrer/Corbalán de Celis, 2004: 25-26.

28 Bauza, 1987: 47-49. Gómez-Ferrer/Corbalán de Celis, 2004: 26.

${ }^{29}$ Gómez-Ferrer/Corbalán de Celis, 2014: 75-93.

30 Falomir, 1994: 28-32, 102-107. 


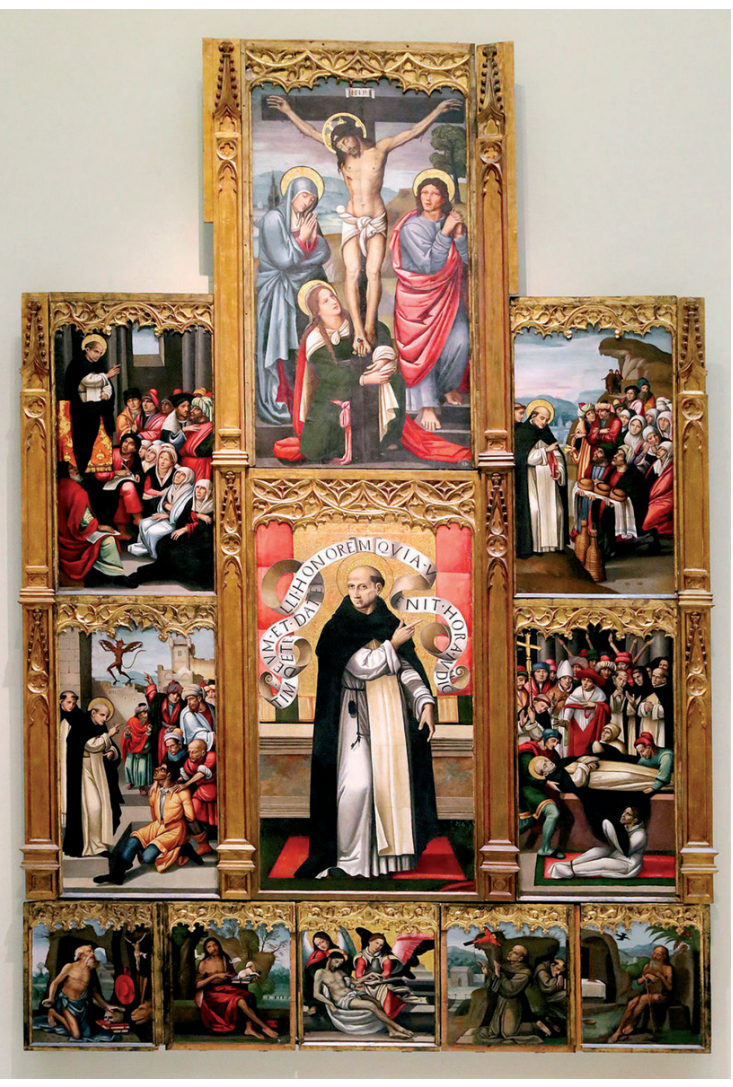

Fig. 5. Retablo de San Vicente Ferrer, Miguel del Prado, Museo de Bellas Artes de Valencia.

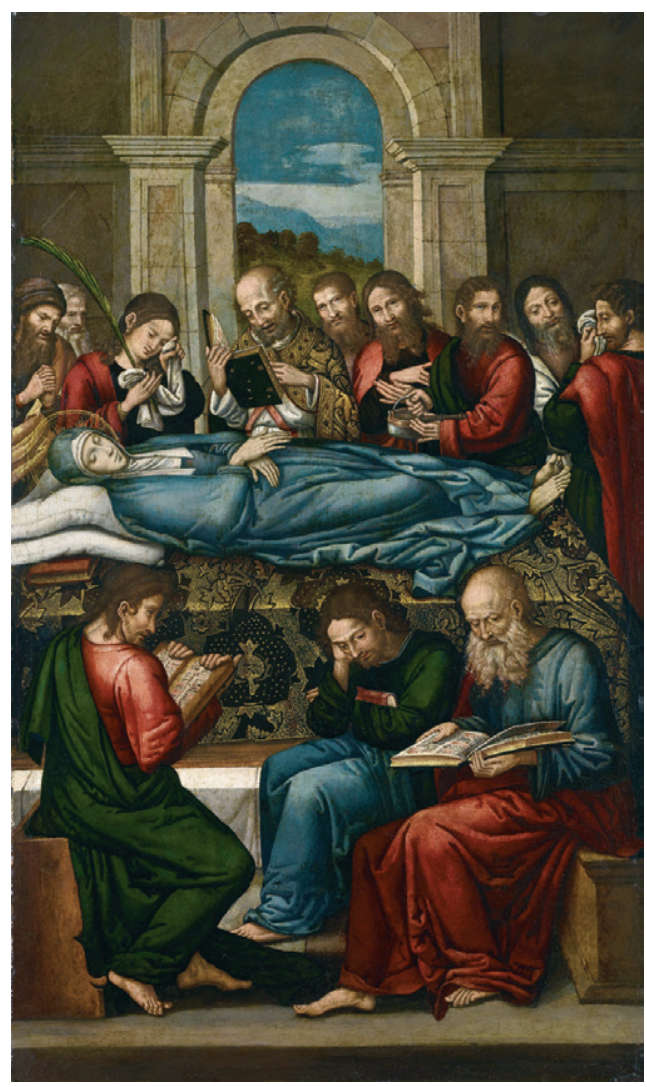

Fig. 6. La Dormición, Miguel del Prado, colección particular.

octubre de $1527^{31}$ sabemos con seguridad que había fallecido, y así lo señala su viuda, Jerónima de la Ras y parte de su familia, que era de origen setabense ${ }^{32}$, como su hermano Antonio Esteve, maestro de obras.

A Miguel del Prado se le identificó con el anónimo maestro del Grifo ${ }^{33}$ que surgió a partir de que Tormo ${ }^{34}$ considerase este nombre de laboratorio para el pintor del retablo de San Vicente Ferrer (fig. 5) que en el Museo de Bellas Artes tiene unos blasones de grifos alados. Procedente de un convento valenciano dedicado a San Onofre, casi con total seguridad el de Museros, cerca de Valencia, al maestro del Grifo se adjudicaron desde entonces una serie importante de tablas, en razón de las similitudes formales ${ }^{35}$. Fundamentalmente una Adoración de los Reyes Magos y la Disputa entre los Doctores de la iglesia de Santo Tomás ${ }^{36}$, las tablas de San Agustín y San Nicolás Tolentino del Museo de Bellas Artes de Valencia ${ }^{37}$, procedentes del convento de San

31 López/Samper, 2006: 144.

32 Gómez-Ferrer/Corbalán de Celis, 2004: 26.

33 Catalá, 1981: 42 recoge la propuesta oral realizada por Carlos Soler d'Hyver sobre esta posibilidad, que retoma también Company, 2006: 382. Propuesta que ha sido admitida por la crítica posterior.

34 Tormo, 1932: 19-24.

35 Post, 1953: 296.

36 Post, 1953: 301.

37 Saralegui, 1944: 34. Post, 1953: 287-288 las atribuía a Felipe Pablo de San Leocadio. Catalá, 1994: 204-207, las relaciona con Miguel del Prado. 
$\operatorname{Agustín}^{38}$, a las que se ha sumado la del Santiago apóstol de la colección Lázaro Galdiano ${ }^{39}$, y quizá del mismo conjunto un calvario del mismo museo valenciano ${ }^{40}$; un San Pedro y un San Pablo del Museo de Bellas Artes de Valencia ${ }^{41}$, La Adoración de los Magos de la colección Quílez ${ }^{42}$, una Adoración de los Magos de la colección Montesinos ${ }^{43}$, varias tablas en colecciones particulares como La Dormición (fig. 6) de la antigua colección Lassala vendida en Sotheby's recientemente ${ }^{44}$, una dormición procedente de Villar del Arzobispo y desaparecida en $1936^{45}$ y varias tablas posiblemente procedentes de un retablo de Torrent, en colecciones particulares o desaparecidas como la de San Cosme y San Damián de los Serra de Alzaga ${ }^{46}$, Santa María Magdalena y Santa Úrsula ${ }^{47}$ de colección particular, San Jorge y San Benito en colección extranjera ${ }^{48}$ y San Bernardo y San Sebastián, desaparecido ${ }^{49}$. Sin ánimo de ser exhaustivos un corpus de obras bastante considerable que diferenciaba a ambos pintores ${ }^{50}$.

Sin embargo, todo este corpus de obras, adjudicado a Miguel del Prado, bastante coherente, no cuadraba con un pintor del que se tenían muy pocas noticias documentales. Prácticamente su mención se reducía a la sociedad tenida con Miguel Esteve y a las referencias de 1521 de la preparación de las Germanías, en las que figuraba junto a otros muchos pintores. No aparecía en las tachas reales y la última noticia mencionada databa de 1537 en que se le nombraba como ya fallecido en un acto relacionado con su esposa Úrsula Gomis y la hija de ambos ${ }^{51}$. En definitiva, muy pocas noticias relacionadas con la profesión de pintor.

Esta ausencia de documentación había hecho que ya en varios artículos y ahora en su reciente tesis doctoral, Vicente Samper ${ }^{52}$ se planteara la posibilidad de adjudicar a Miguel Esteve, pintor claramente documentado, conocido como autor de retablos ciertamente significativos y al que los jurados inicialmente habían encargado el conjunto de la capilla de la casa de la ciudad, como el pintor al que se le debía adjudicar la obra correspondiente a Miguel del Prado. Se señalaba que la diferenciación marcada un tanto arbitrariamente por Tramoyeres y que se había mantenido, no correspondía a una realidad pictórica ya que no era posible advertir dos manos distintas en los lunetos y mucho menos adjudicar a uno u a otro los mismos. Ante esta situación, la propuesta que se planteaba era la de atribuir todo el corpus; es decir, todo lo anteriormente considerado de Miguel Esteve y todo lo que se había considerado como Miguel del Prado, a un único pintor. Este sería Miguel Esteve dado que fue al que primero se encargó la obra de la ca-

\footnotetext{
38 Sabemos de la existencia de la capilla de San Nicolás de Tolentino en la iglesia de San Agustín y que en 1498 ostentaba el patronato de esta capilla Juan de Gallach, citada en su testamento de 1498, Archivo del Reino de Valencia (ARV), notario: Joan Comes, signatura: 601. Pero desconocemos la cronología del retablo, ya que en el testamento no hay referencia alguna a la dotación de la capilla. Saralegui, 1955: 332, señala el catálogo del Museo de 1847 con el n. ${ }^{\circ} 413$ como procedentes del convento de San Agustín, el San Nicolás y San Agustín con el n. ${ }^{\circ} 410$ del catálogo impreso de 1850

39 Samper, 1998: 274-276.

40 Catalá, 1994: 207. Benito, 2006: 226-227.

41 Benito, 2006: 224-225.

42 Company/Puig, 2014: 126-137.

43 Post, 1953: 303-304.

44 Tramoyeres, 1919: 87 la publica como obra de los Hernandos. Post, 1953: 329, consideró que era obra dudosa de Miguel Esteve, con posterioridad se ha dado como de Miguel del Prado y como tal aparece en Sotheby's, 2014.

45 Post, 1953: 39-40 la consideraba de San Leocadio, pero Company, 2006: 349, indica que debe ser de Miguel Esteve o Miguel del Prado.

46 Benito, 2006: 220-221.

47 Benito, 2006: 222-223. Estuvo en la colección Lacuadra, se pensaba que podría proceder del mismo retablo que las piezas de San Agustín. Samper en 2006 propuso que procedían de un retablo de la iglesia de Torrent, compañeras del San Bernardo y San Sebastián en su día indicado por Post: 1953, 307.

48 Gómez Frechina, 2014.

49 Post, 1953: 307.

50 Post, 1953: 302, incluía como obras del Maestro del Grifo, las alas de un tríptico de Lucena del Cid; Saralegui, 1955, añadía también un San Cristóbal. Lámina II, 331-333.

${ }^{51}$ Cerveró, 1966: 29.

52 López/Samper, 2006. Samper, 2013: 106; 2015.
} 
pilla y del que se tenían mayor número de noticias y referencias. Miguel Esteve pasaba a ser el autor de todo este conjunto de obras. Esta posibilidad implicaba que todo este corpus fuera obra de un único pintor y que las variaciones de estilo se hubieran producido en razón de una evolución pictórica que se habría llevado a cabo en los 20 años de teórica actividad documentada de Miguel Esteve, entre 1508 y 1527, y en la posible participación de un taller. Pero estamos en disposición de ofrecer una serie de nuevas referencias que nos deben llevar a reconsiderar lo conocido sobre ambos pintores y que quizá sirvan para matizar esta propuesta, que prácticamente anula a Miguel del Prado y lo convierte en un mero colaborador sin personalidad propia.

\section{El contrato para el retablo de la capilla del Roser de Santo Domingo de Valencia con Miguel del Prado}

Como hemos señalado, las noticias documentales sobre Miguel del Prado eran muy escasas, conociéndose prácticamente solo que había colaborado con Miguel Esteve en los lunetos de la casa de la ciudad, que había participado en las reuniones de preparación para las Germanías y que había fallecido en torno a 1537. Esto nos daba un lapso de unos 18 años de actividad pictórica, entre 1519 y 1537 sin que se encontrara su nombre en ninguno de los documentos exhumados de los archivos valencianos. No aparecía en las tachas de pintores de la ciudad, ni en ninguna otra referencia pictórica o no. Se desconocían encargos independientes al margen de la sociedad con Miguel Esteve y esto había conducido a reconsiderar su personalidad, pensando en lo ilógico de adjudicarle toda la obra del Maestro del Grifo. Su ausencia en estas tachas reales se podía explicar porque en esta fecha fuera aún muy joven y fuera un pintor colaborador en un taller de otro maestro, o porque siendo presumiblemente un pintor castellano hubiera llegado a la ciudad en fecha posterior. Su posible juventud o pertenencia a otro taller se había superado en 1519, porque si no, no hubiera podido firmar una compañía en calidad de pintor independiente, con personalidad jurídica propia.

En primer lugar se había señalado que de Miguel del Prado no se conservaba ninguna noticia relacionada con su actividad como pintor de retablos. Es más, el contrato por el que Miguel Esteve solicita la colaboración de Miguel del Prado en 1519, diferencia en su forma de nombrarlos a uno y a otro. Mientras que Miguel Esteve aparece como "pintor de retaules" de Miguel del Prado, solo se dice que es pintor. Pero por los documentos que vamos a proporcionar sabemos que al menos se conoce un contrato como pintor de retablos aunque al final es una obra que no pudo concluir porque falleció antes de poder si quiera comenzarla.

Se trataba del retablo para la capilla situada a la izquierda de la entrada de la iglesia del antiguo convento de Santo Domingo de Valencia (fig. 7) y dedicada a la Virgen del Rosario que había sido construida a finales del siglo XV y principios del siglo XVI por Pere Compte y Miguel de Maganya y que posteriormente se había entregado en patronato a los Sorell ${ }^{53}$. La capilla gótica fue ampliada en 1686 por el arquitecto Juan Pérez Castiel y como casi la totalidad del templo, sería posteriormente demolida tras la desamortización en el siglo XIX. Sobre esta capilla hay una abundante documentación que no ha sido tenida lo suficientemente en cuenta y documentación inédita que es la que ahora se aporta.

La capilla que se había venido construyendo desde 1491 se concluía hacia 1514. El 23 de octubre de 1514 los conventuales de Santo Domingo firman un contrato con Baltasar Sorell para permitirle ostentar el patronato, hacer vaso y sepultura para trasladar y enterrar a los miembros de su familia. En este momento se preveía hacer unas gradas para acceder al altar mayor, construir una barandilla de piedra y una gran reja de hierro, terminar unas claraboyas sobre el enrejado y sobre todo, dotar a la capilla de un gran retablo ${ }^{54}$. A partir de aquí se conocía que los

53 Gómez-Ferrer, 2003: 193-197.

${ }^{54}$ APPV, notario: Cristóbal Fabra, signatura: 24305, 23 de octubre de 1514, “(...) Ítem e mes es pactat ut supra que lo dit magnific mosen Baltasar Sorell aga de fer lo retaule de al dita capella axi de fusta com de pintura tal qual per a la dita capella es necesari (...)”. 


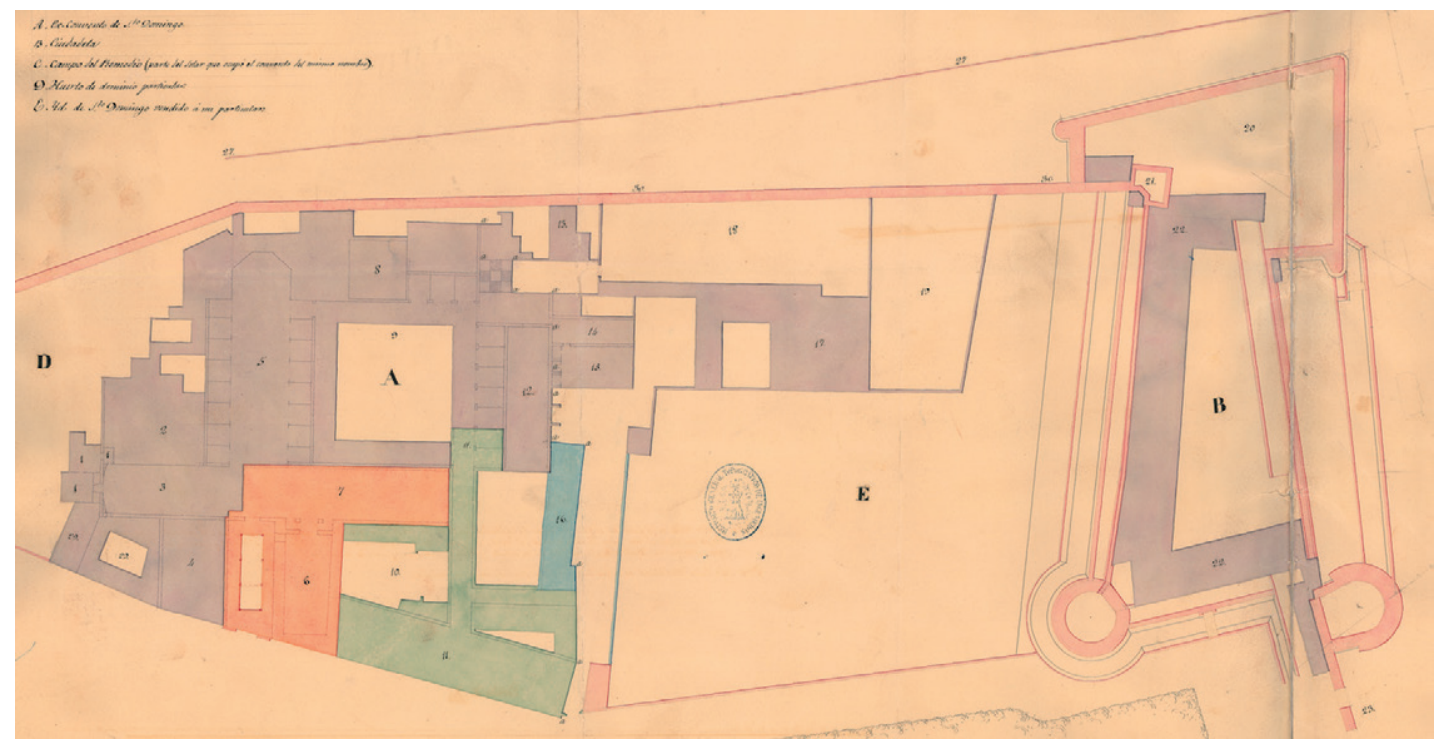

Fig. 7. Plano del exconvento de Santo Domingo de Valencia, n. ${ }^{\circ}$, Capilla del Rosario, Vicente Casanovas, 1847, Archivo Militar General.

Sorell habían incumplido con parte del contrato y Teixidor ${ }^{55}$ nos recordaba que los problemas se habían sucedido quejándose los conventuales ya en 1518 diciendo que los Sorell no habían hecho nada, lo que desembocó en un pleito en 1533 que indicaba que el enrejado era "de mala gracia" y que las claraboyas estaban hechas con yeso y de mala manera. Finalmente, se sabía que Luis Sorell había contratado con Onofre Falcó y Paulo Rigo la pintura del retablo en $1538^{56}$. Retablo que se debió sustituir cuando la cabecera de la capilla se modificó en el siglo XVII.

Lo cierto es que los Sorell sí que habían iniciado las labores de la capilla, al menos en lo que al retablo se refería, pero había quedado sin acabar por diversas circunstancias. El 5 de diciembre de $1514^{57}$ se contrató un gran retablo de madera con el carpintero Damià Gonsales que se comprometía a construir una estructura de 27 palmos de altura y 17 de anchura, con un total de catorce figuras en los pilares que separaban las distintas casas donde se albergarían las pinturas, con un Araceli en el medio rodeado de doce serafines y con los cuatro evangelistas en los laterales, una gran espiga en lo alto y un banco de cinco casas, todo a la romana. El plazo para su ejecución era de un año y medio y por él recibiría el precio de 125 libras.

El retablo debió concluirse en un plazo relativamente razonable ya que el 26 de diciembre de 1517 se estaba en condiciones de firmar los capítulos para su pintura ${ }^{58}$. Y este es el contrato que

55 Teixidor II: 1755 (edición de 1949) 71-80, “que en esta capella los Sorells may han fet res"; en el pleito de 1533 se dice "que los Sorells han fet reixat prim de mala gracia y aquelles claraboyes de algeps".

56 Martínez Rondan, 1998: 109-111.

57 APPV, notario: Cristóbal Fabra, signatura: 24305, 5 de diciembre de 1514, “(...) Ço es que aquell dit retaule a de esser de bona fusta e a de tenir vint y set pams de altaria e deset pams de ample e a de tenir tres partiments en cascun (roto) tres pillars en cascun pilar una ymatge de gran del pillar fins al capitell ab sa vassa entre un pillar e altres les quals ymatges dels pillars prenen suma de son quatorze en nombre e sa espiga quadradas dos pillars e ses ymatges a a fer obres mortes e ab sa obra juxta en la spiga del dit retaule segons una mostra feta e deboxada de la mostra e figura del dit retaule de ma del dit mestre Damià Gonsales ab son Araceli en lo mig del dit retaule ab dotze serafins en lo mont e los quatre evangelistes en los dos costats del Araceli e en lo banch del dit retaule a de haber cinch departaments e en cascun departament un pilar ab ses vases alt e bax a la romana responent tot al sobre dit retaule (...)".

58 APPV, notario: Cristóbal Fabra, signatura: 24307, 26 de diciembre de 1517. Contrato con Miguel del Prado. 
no se conocía sobre esta capilla. Es un contrato firmado con el pintor Miguel del Prado para pintar tanto los elementos de madera del retablo, esencialmente las catorce imágenes de bulto que había tallado Damià Gonsales, el Araceli con su nicho azul y estrellas doradas y las imágenes de los serafines y evangelistas, todo ello con dorados de calidad. Pero además, debía pintar los cuadros de los gozos de la Virgen o lo que Baltasar Sorell eligiera en el cuerpo del retablo y el banco del retablo con historias elegidas también por don Baltasar Sorell. Esta obra debía quedar terminada a fines del año 1518 y por ella debía cobrar un total de 250 ducados de oro. Miguel del Prado daba como fiadores del contrato a los plateros Ferrando de Tapia y Martí García.

Con posterioridad, volvemos a encontrar prácticamente la misma capitulación que la firmada con Miguel del Prado, pero esta vez con el desconocido pintor Petrus Ramón, habitante de Valencia, el 26 de noviembre de 1522, arguyendo que el pintor Miguel del Prado había fallecido y no lo había podido realizar ${ }^{59}$. Por razones que desconocemos esta capitulación tampoco se cumplió y el retablo fue de nuevo contratado en casi idénticos términos en 1538 por Onofre Falcó y Pablo Rigo, que son los que finalmente ejecutan las pinturas. El contrato para el retablo de 1538 es muy similar, se vuelven a especificar las dimensiones del conjunto realizado a la romana, las catorce figuras de bulto y el araceli, aunque los motivos pictóricos se detallan algo más. El banco queda definido con la piedad en el centro y dos historias de la Pasión a cada lado. Las escenas del cuerpo principal eran tres gozos de la Virgen a cada lado de la escena principal que era la Asunción de Nuestra Señora y en la espiga la crucifixión con San Juan y María Magdalena. Se ha considerado que la Virgen del Rosario que se conserva en los almacenes del Museo de Bellas Artes de Valencia, con el n. ${ }^{\circ}$ de inventario $509^{60}$, quizá pudo pertenecer a este retablo.

Por tanto, esta noticia viene a romper con algunos de los esquemas que existían sobre Miguel del Prado. En primer lugar adelanta en dos años la fecha de su presencia en Valencia, en segundo lugar lo sitúa como pintor de retablos recibiendo un importante contrato y en tercer lugar, modifica totalmente la fecha de su fallecimiento. Sobre este último aspecto ampliaremos también noticias. Vamos ahora sobre los dos primeros.

El contrato de un retablo de dimensiones importantes y para una capilla significativa por unos nobles como los Sorell, por un precio nada desdeñable, nos hace sospechar de la importancia de Miguel del Prado como pintor de retablos ya en esta fecha. No podemos imaginar un contrato de estas características con un aprendiz o con alguien sin una cierta reputación. Sí que lo imaginamos con un artista de cierto renombre como el que debía tener por entonces Miguel del Prado y con una personalidad propia deslindada del taller.

Las razones para no poder formalizar el contrato en el tiempo estipulado pudieron ser varias, ya que Miguel del Prado se debió entretener con el trabajo de la capilla de la casa de la ciudad, que era un encargo municipal y también muy prestigioso que le requería una importante dedicación y seguramente le dio prioridad. Aunque el contrato firmado para la compañía con Miguel Esteve es de 9 de abril de 1519, en realidad, Miguel del Prado debía estar colaborando desde tiempo antes, porque ya en esa fecha, Esteve le había pagado 25 libras. Por otro lado, la peste que había asolado la ciudad en el verano de 1519 y la situación laboral que se empezaba a complicar con el ambiente que preludiaba el levantamiento de las Germanías que a la postre sería lo que impidió el cumplimiento del contrato, pudieron impedir el trabajo del mismo. El retablo sabemos que estaba acabado en la madera y que no debió ni siquiera empezar a prepararlo para poder recibir la pintura pues ni el encolado ni el enyesado se hicieron y se vuelven a capitular

59 APPV, notario: Cristóbal Fabra, signatura: 24311, 26 de noviembre de 1522, “(...) et cum propter prevencionem mortis que evenit dicto Miquaelli del Prado pro parte illius non potest ad impleri ob dictam causam. Nos supradicti contrahentes inter nos venimus in concordiam e pactum solempni estipulacione vallatum et ego dictus Petrus Ramon promitam denpingere supradictum retabulum (...)" y se repite el contrato en los mismos términos que el anterior.

60 Marco, 2013: 484-485. En la ficha del catálogo de esta exposición sobre la Virgen del Remedio de Benicarló se publica fotografía de esta tabla, sin aludir al contrato de Onofre Falcó y Paulo Rigo, situándola antes de 1514, y relacionándola de forma poco fundamentada desde nuestro punto de vista con el pintor portugués Pere Nunyes $(+1554)$. La similitud estilística entre ambas tablas y dado que la de la Virgen del Rosario está documentada hace pensar en la posibilidad que la de Benicarló sea también del entorno de Onofre Falcó. 
con posterioridad con el desconocido Petrus Ramón. Este pintor tampoco lo hemos localizado en ningún documento y no sabemos las razones de su incumplimiento. La otra referencia que nos proporciona el contrato es la relación de Miguel del Prado con los plateros Ferrando de Tapia y Martí García a quienes cita como fiadores. Aún así no hemos encontrado a Miguel del Prado mencionado en otra documentación sobre los plateros, mientras que debemos recordar que Miguel Esteve sí que actuó como testigo en el conflicto del gremio de plateros con los Forment. Desconocemos si la relación con los plateros le pudo venir de entonces, aunque él no figurara como testigo independiente, pero quizá pudo estar ya asociado al taller de Miguel Esteve del que luego se pudo independizar. Lo cierto es que una relación directa con los plateros hasta el punto de darlos como fiadores indica un contacto importante con ellos. Como hemos avanzado Miguel del Prado no cumplió con la obra porque murió. Este dato modifica totalmente la cronología de este pintor, que vamos a tratar de precisar.

\section{Miguel del Prado y la Germanía}

La cronología sobre Miguel del Prado que se venía manejando hasta ahora, daba como fecha de su fallecimiento el año 1537, citando un documento publicado por Cerveró en el que figuraba su mujer Úrsula Gomis y la hija de ambos, Ángela Prado y Gomis, haciendo una declaración. A partir de este documento se había establecido en torno a esa fecha el fallecimiento de este pintor. Por tanto, según estos datos habría sobrevivido en casi más de 10 años a Miguel Esteve, al que sabemos muerto en 1527.

Sin embargo, el 22 de noviembre de 1522, fecha de contratación del retablo del Roser por parte de Petrus Ramón, se señala que del Prado ya ha fallecido, por lo que con seguridad se adelantaba en más de 15 años su defunción. Pero podemos llegar a precisar incluso con exactitud las causas y asociarlas a la problemática de la Germanía, dando a conocer con claridad la implicación de algunos de los pintores en esta revuelta que como en el caso de Prado le condujo hasta la muerte.

De hecho las últimas referencias documentadas sobre Miguel del Prado se corresponden con dos textos que tienen relación con el movimiento agermanado. El primero es la reunión del 15 de junio de 1521 de un numeroso grupo de pintores en la Cofradía de Belén para elegir a Nicolau Falcó, síndico, y otorgarle plenos poderes para que solicitara de las autoridades municipales permiso de armas para poder unirse a la Germanía. En esta reunión figura su nombre de forma individualizada junto al de otros numerosos pintores. El segundo documento se fecha al día siguiente cuando los pintores reunidos en la casa de los plateros de la ciudad eligen a Joan Caro como capitán en vísperas de acudir a la batalla de Gandía.

La historiografía más reciente ya ha destacado el papel que tuvo el pequeño artesanado y los gremios urbanos en la revuelta. Previa a estas reuniones directamente relacionadas con la Germanía, ya habíamos mencionado el intento de los pintores el 5 de diciembre de 1520 en poder constituirse en colegio y universidad. Un intento de agrupación de los pintores que no disponían de representantes propios entre los gremios de la ciudad, y carecían de fuerza en el ámbito social, en contraste con canteros, obreros, carpinteros o plateros que sí disponían de gremios claramente diferenciados y estaban representados en el Consejo Municipal. En el intento de creación de un colegio de pintores solo se mencionan cuatro nombres entre los que no se encuentra Miguel del Prado, y sí Miguel Esteve, lo que ha hecho pensar en el mayor prestigio de este último. De todas formas esto tampoco es muy fiable porque en realidad son los síndicos de ese momento, y junto a Esteve y Falcó, reconocidos retablistas, figuran unos menos conocido Jaume Beltrán y Joan Cardona. En estos años, el intento de agrupación de pintores incluía todo tipo de profesionales, los retablistas, pero también los cortineros. Este proyecto de asociación constituía un nexo de unión previo al movimiento ligado directamente a la Germanía.

La implicación de los distintos colectivos relacionados con las artes ha sido cuestionada por los estudiosos de la Germanía que finalmente no veían que hubiera habido una actividad muy intensa por parte de éstos, sobre todo si se comparaba con los gremios relacionados con el textil 
como los "perayres", "texidors" y "velluters" ampliamente representados. Hasta ahora sabíamos de la participación directa de algunos pintores como Antoni Cabanes de Xàtiva al que al acabar la Germanía se le confiscaron los bienes, fue declarado fugitivo y ya no se vuelve a documentar nunca más ${ }^{61}$. Otros se implicaron mucho más directamente como Gaspar Godos que llegó a formar parte del Comité de Justicias para guardar la ciudad ${ }^{62}$ y colaboró además con la realización de banderas y estandartes pintando la bandera de los labradores de Vilafames en febrero de $1521^{63}$. De hecho sabemos que algunos agermanados llevaban banderas pintadas como el franciscano Fray García de Xàtiva que portaba una bandera con un crucifijo pintado en ella ${ }^{64}$. Sin embargo, no parecía que el papel de este colectivo hubiera sido muy activo ya que las multas o composiciones que se realizaron con posterioridad, no afectaron a los pintores.

Pues bien, ahora sabemos que algunos llegaron a pagar el precio de su propia muerte en el campo de batalla. Y esto es precisamente lo que sucedió con Miguel del Prado. El 21 de junio se hablaba de la posible participación de los pintores en la batalla de Gandía, que tuvo lugar el 25 de julio de 1521 con éxito de las tropas agermanadas que derrotaron al ejército del virrey conde de Mélito. Sin embargo, algunos no pudieron siquiera acudir a esa batalla ya que habían marchado unos días antes a la de Morvedre. Ésta acaeció el 18 de julio de 1521 y se saldó con un desastre para las tropas agermanadas, encabezadas por Jaume Ros, contra las tropas del Duque de Segorbe, cifrándose la pérdida en unos 2000 hombres. Sería precisamente en esta batalla conocida también como Batalla de Almenara donde perdería la vida Miguel del Prado, batalla que como nos señala el cronista Viciana "por muerte de tanta gente de la ciudad había muy grande planto y llanto"65. El texto del dietario de Jerónimo Soria mucho más explícito recoge la crudeza de la batalla: "E dijous apres seguent de mati a XVIII de dit Juliol, 1521, feren resenya en Morvedre e veren que y avia sis milia omens de pelea, tots a peu, de que feta resenya partiren de Morvedre pera Almenara y essent en vista de Almenara, obra de hun quart de llegua, trobaren lo Duch de Sogorp en camp, ab obra de quatre milia homens, entre catalans y moros, e dosents de cavall e quant vingue a les onze ores de mig jorn, tocaren a l'arma, los huns els altres, e de fet, pelearen fins a la huna ora apres mig dia, de que sumaven que de huna part e de altra moriren dos milla homens, de que mori molta morisma, e de la part de Valençia mori molta gent e molts caps de cases, menestrals molt honrats, entre nafrats y ofegats" 66 .

La declaración que publicó Cerveró en la que figuran la esposa e hija de Miguel del Prado era en realidad un pleito contra Miguel Jerónimo escribano tutor y administrador de la herencia de Miguel del Prado, nombrado porque éste había muerto sin testar ${ }^{67}$. Las causas de la falta de testamento precisamente eran debidas a que había fallecido en las Germanías en la Batalla del camp de Morvedre, tal y como testifican aquellos que le conocieron, a instancias del marido de su hija, el velluter Joan Gomis. Tanto el pintor Pere Cabanes como el notario Nofre de Cas ${ }^{68}$, responden que "(...) es ver que en la batalla del camp de Morvedre lo dit Miquel Prado es mort e passat de la present vida en l'altra e que no havia oit dir que aquell haja fet testament ni altra disposició ni darrera voluntat de sos bens" ${ }^{\prime 9}$.

61 García Cárcel, 1975: 248.

62 García Cárcel, 1973: 138.

63 Gómez-Ferrer, 2010: 357.

${ }^{64}$ Durán, 1982: 60.

65 Viciana (1566, edición de 2005): Libro Quarto: 386.

66 Soria (1559, edición de 1960): 49.

${ }^{67}$ Cerveró, 1966: 29. ARV, Justicia Civil, 3833, Mano XII, folio. 12. 5/XI/1537. Cerveró solo copió el encabezamiento, pero el documento contiene todo el conjunto de declaraciones sobre las causas del pleito, en que se certifica que "Miquel Prado quondam pintor es mort e pasat de la present vida en l'altra sens haver fet ne ordenar testament ne altra ultima voluntat".

${ }_{68}$ ARV, Justicia Civil, 3833, Mano XII, Nofre de Cas, notario, testifica que "Lo dit Miquel Prado estant en lo camp de la vila de Morvedre, aquel morí".

${ }^{69}$ ARV, Justicia Civil, 3833, Mano XII, Declaración de Pere Cabanes, pintor, habitador de la ciutat de Valencia. 
Por tanto, sabemos que Miguel del Prado se había casado con Úrsula, que habían tenido una hija de nombre Ángela que en 1537 estaba casada con el velluter Joan Gomis ${ }^{70}$. Posiblemente, Miguel del Prado debía ser relativamente joven cuando marcha a la batalla, y no debió preparar testamento alguno. La relación de testigos entre los que se encuentra Pere Cabanes hace pensar que se podrían haber conocido desde esa época de la Germanía, recordemos que en el momento de la testificación, hacía más de 16 años de esa batalla, y que quizá pudo tener algo que ver con el taller de los Cabanes. En la fecha en que Cabanes está testificando a favor de la familia de Miguel del Prado, se trata de Pere Cabanes hijo, quien está mencionado de forma claramente diferencia de su padre, entre los pintores reunidos en la cofradía de Belén en los días previos a las dos sangrientas batallas ${ }^{71}$. Podemos plantearnos una posible formación de Miguel del Prado en el taller de Pere Cabanes, aunque no nos aporta muchos datos este hecho, toda vez que a pesar de los posibles intentos de identificación con el Maestro de Artés, no hemos aclarado aún los entresijos de este taller. Por otro lado, puede ser que 16 años después de la reunión se decidiera contar simplemente con algún pintor joven que aún pudiera testificar porque otros muchos de los citados en esta reunión, en 1537 ya debían haber fallecido.

Por otro lado, esta fecha segura de la muerte de Miguel del Prado en 1521 nos hace reducir enormemente la cronología, — más de 16 años - y nos debería resituar al respecto de las posibles obras que se le atribuyen, ya que a partir de este momento, solo tenemos 4 años documentados de posibles trabajos de Miguel del Prado como pintor independiente, entre 1517 que contrata el retablo para la capilla del Roser y 1521, fecha en que muere. Aunque hemos de considerar que en los años anteriores a 1517 debería haber realizado también pinturas, aunque no nos conste documentalmente, para poder explicar un contrato de la importancia del que firmó con Baltasar Sorell. La dificultad que encierra el poder analizar en profundidad este dato es que ninguna de las obras atribuidas a Miguel Esteve o a Miguel del Prado tienen una cronología clara. En ellas se aprecia una relación bastante directa con las aportaciones de Pablo de San Leocadio y los Hernandos, todas ellas posibles antes de 1521, por tanto, no podemos tampoco descartar ninguna hipótesis para la identificación ya que no tenemos ninguna obra atribuida que sepamos con seguridad que es posterior a 1521. La única pieza a la que se le ha intentado dar una cronología posterior a esta fecha es el retablo de San Vicente del Museo de Bellas Artes de Valencia, ya citado y procedente del convento de San Onofre ${ }^{72}$, en cuya predela hay un Cristo yacente del que se ha señalado su dependencia con respecto a la obra del Piombo. El Cristo muerto sostenido por ángeles que preside el centro de la predela de este retablo es un trasunto del Cristo de la Lamentación del centro del tríptico de Sebastiano del Piombo que perteneció a la colección del Embajador Vich.

Hasta ahora se había datado en fecha necesariamente posterior a la de 1521, año de la posible presencia del tríptico de Piombo en Valencia tras el regreso del Embajador Vich. Sería además muy improbable en los años de la Germanía por lo que se había propuesto retrasar la realización de este retablo a algún momento posterior a fines de 1521 o ya en 1522, en que se reanuda de forma clara la actividad artística en una ciudad que va recuperando el pulso tras la revuelta. Al tratarse de una de las primeras obras que seguía directamente el modelo piombesco, más tempranamente incluso que el retablo de la misma advocación para Segorbe de Vicente Macip que se fecha a partir de 1523, era por tanto un retablo importante, porque además reunía toda la producción del Maestro del Grifo. Si aceptáramos esta propuesta quedaría resuelto el enigma y las obras del Maestro del Grifo podrían pasar sin ningún género de dudas a Miguel Esteve.

70 ARV, Justicia Civil, 3833, Mano XII, “(...) E primerament diu e posa que matrimonio fonch contractat en faç de Santa Mare Esglesia, entre lo honrat en Miquel Prado, quondam pintor e Na Ursola, muller de aquell, e del dit matrimoni procrearen una filla llegitima e natural e la dita Na Angela Prado e de Gomis, muller den Joan Gomis velluter".

71 Falomir, 1994: 106-107. El Pere Cabanes de 1537 es hijo de Pere Cabanes I y está documentado al menos hasta 1552 .

72 Momblanch, 1966, señala que se realizó por expreso deseo de Fray Juan de Enguera tras su fallecimiento en 1513. Al ser ésta una fecha temprana tampoco nos resuelve la duda de la cronología para este retablo. 


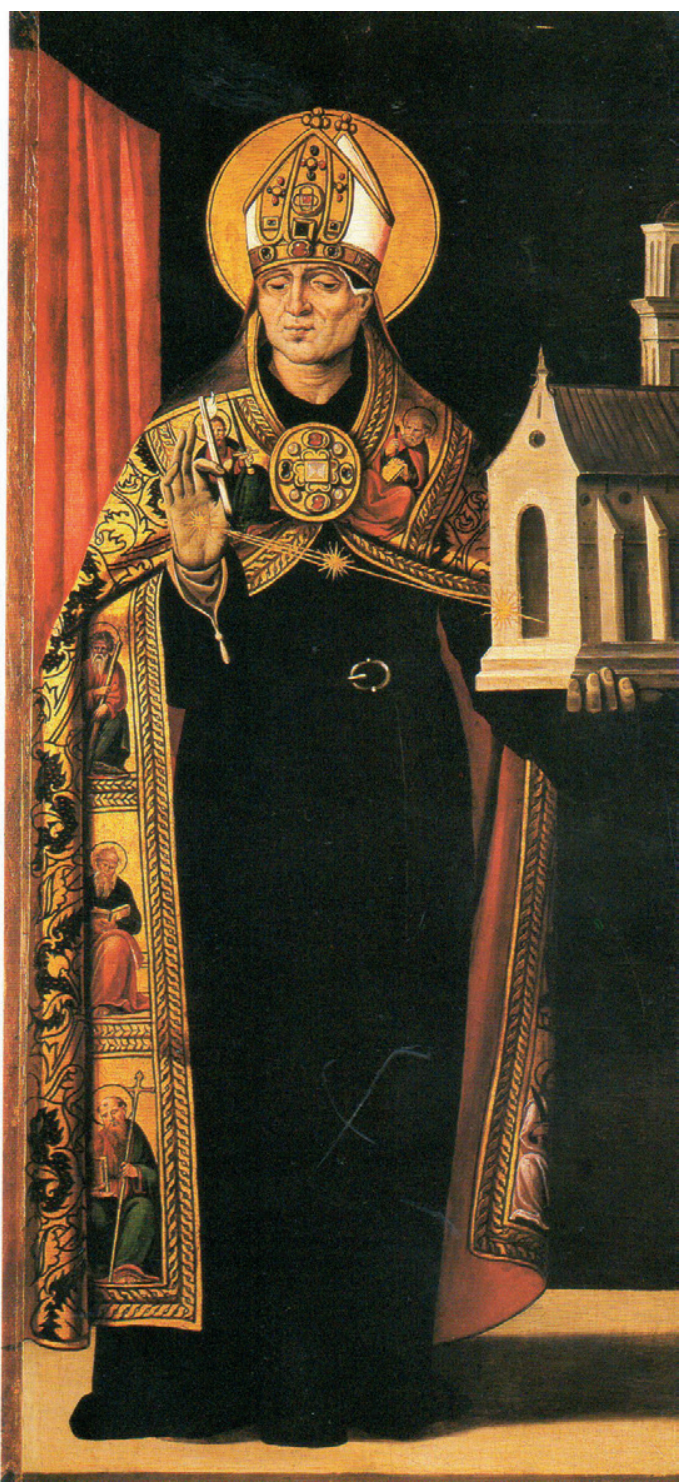

Fig. 8. San Agustín, Miguel del Prado, Museo de Bellas Artes de Valencia.
Pero recientemente se ha abierto una nueva hipótesis ${ }^{73}$ sobre la fecha de llegada de las obras de Piombo a Valencia, barajándose la posibilidad de que hubieran llegado en torno a los años 1516-17 cuando el embajador, aún en Roma, y su hermano el cardenal Guillem Ramón de Vich estaban impulsando la construcción de una nueva iglesia y el uso de su cabecera como panteón funerario de la familia en el convento de la Murta (Alzira). Coincide también con el momento en que Jerónimo de Vich se plantea la posibilidad de regresar a su tierra natal, a la muerte del rey Fernando el Católico en enero de 1516. La pieza central del tríptico, La Lamentación ante Cristo muerto está firmada y datada por Piombo en 1516 y el Cristo Portacruz se fecha en torno a esta misma cronología. Esta nueva vía de investigación explicaría que ya en obras valencianas realizadas con anterioridad a 1520 se advirtiera la influencia directa de Piombo, como sucede en la tabla de la Flagelación de Fernando Llanos de la colección Orts-Bosch ${ }^{74}$. Llanos al acabar las puertas del retablo de la catedral y otros encargos, se traslada a Murcia donde se le documenta a partir de 1514, 1515 y 1516 fecha que aparece en la tabla de los Desposorios; tras un paréntesis documental, vuelve de nuevo a Murcia en 1520, donde fallece en 1525. Este paréntesis se colma con un regreso a Valencia donde se encuentra en mayo de $1517^{75}$.

La Flagelación se asocia a una Oración en el Huerto de Felipe Pablo de San Leocadio con la que hace pareja y debió de ejecutarse para algún lugar de Valencia en torno a esas fechas, entre 1517 y 1520 . Sin duda es obra realizada tras la contemplación del Cristo Portacruz de Piombo pues reproduce el soldado con el casco de forma casi literal ${ }^{76}$. Si aceptamos por tanto esta propuesta y pensamos que estas tablas estuvieron en Valencia en torno a los años 1517-20, seguimos sin poder resolver el enigma puesto que el retablo de San Vicente podría haber sido pintado en fecha anterior a 1521 y por tanto anterior a la muerte de Miguel del Prado, por cualquiera de los dos pintores.

\footnotetext{
73 Gómez Frechina, 2016. Agradecemos la consulta del texto que se encuentra en prensa a su autor.

74 Benito, 2006.

75 Gómez-Ferrer/Corbalán de Celis, 2006.

76 Benito, 2006: 54 .
} 
Sí que podemos cerrar el círculo de un fallecimiento de ambos en la década de los 20, Miguel del Prado en 1521 y Miguel Esteve antes de octubre de 152777, —recordemos que tampoco conocemos la fecha exacta - simplemente que ya no vive. Tampoco sabemos si Miguel del Prado procede de Castilla, y como otros pintores llega a Valencia desde esta zona. En los contratos suscritos con los jurados a Miguel Esteve se le cita como ciudadano de Valencia, mientras que a Miguel del Prado solo se le menciona como habitante de la ciudad, hecho que nos podría hacer pensar en un origen castellano. Recordemos que los propios Hernandos son pintores castellanos como al parecer también lo fueron otros retablistas de esta época. Una posible procedencia podría ser la villa de Villar del Prado en el sur de la actual comunidad de Madrid, y cercana ya a tierras de Toledo, donde luego se documentarán otros pintores con este apellido como el afamado Blas de Prado. Pero, realmente esto es una suposición, que por el momento no hemos podido verificar.

La mayor dificultad por el momento reside pues en las recientes hipótesis esgrimidas que anulan totalmente la personalidad de Miguel del Prado traspasando toda su obra a un único pintor que sería Miguel Esteve. De momento, no podemos saber quien de los dos pinta cada una de las obras adscritas a uno y a otro, pero lo que sí parece probable es que se trata de dos pintores bastante diferenciados. Uno con unas referencias y cercanía a los Hernandos y de una calidad mucho mayor, que podemos estar de acuerdo con que sea Miguel Esteve porque parece ser el de más renombre y el que recibe inicialmente el encargo de los jurados de la ciudad. Pero hay también otra mano de un pintor mucho más rígido y con mayores dificultades para resolver composiciones que sería el autor del conjunto de los Agustinos (fig. 8), y de otras piezas anteriormente adscritas al Maestro del Grifo. Lo que no nos parece posible es traspasar todo el corpus pictórico de uno a otro y considerar todo el conjunto obra de una única mano. Creemos que las obras son muy desiguales y que esta tesis tampoco ayuda mucho a comprender el difícil período de este primer cuarto del siglo XVI en la pintura valenciana.

\section{BIBLIOGRAFÍA}

Bauza, Nicolás (1987): “Un retablo para el altar mayor del monasterio de la Valldigna en 1519”. En: Archivo de Arte Valenciano, Valencia, pp. 47-49.

Benito, Fernando (2006): "Hernando Llanos, Flagelación", en La col.lecció Orts-Bosch al Museu de Belles Arts de València. Valencia: Generalitat Valenciana, pp. 54-55.

Benito, Fernando/Gómez Frechina, José (2006): La Memoria recobrada, pintura valenciana recuperada de los siglos $X I V-X V$. Valencia: Generalitat Valenciana.

Benito, Fernando/Gómez Frechina, José: (2009) La edad de oro del arte valenciano. Rememoración de un centenario. Valencia: Generalitat Valenciana.

Catalá, Miguel Angel (1981): Colección Pictórica del Excmo. Ayuntamiento de Valencia, 1. ${ }^{a}$ Parte. Valencia: Ayuntamiento de Valencia.

Catalá, Miguel Angel (1994): "San Agustín “ y "Sagrada Familia en el taller de San José”, en El Mundo de los Osona, Valencia: Generalitat Valenciana, pp. 204-211.

Cerveró, Luis: (1966), "Pintores valentinos, su cronología y documentación”, en: Archivo de Arte Valenciano, p. 29.

Company, Ximo (1987): La pintura del Renaixement, Alfons el Magnànim, Valencia.

Company, Ximo (2006): Paolo de San Leocadio i els inicis de la pintura del Renaixement a Espanya, Gandía: CEIC, Alfons el Vell.

Company; Ximo/Isidro Puig (2014): “Una adoración de los Reyes Magos de Miguel del Prado (siglo XVI)”, en: Ars renovatio, pp. 126-137.

Durán, Emilia: (1982): “Aspectes ideològics de la Germania”, en: Pedralbes, pp. 53-67.

Falomir, Miguel (1994): La pintura y los pintores en la Valencia del Renacimiento, Generalitat Valenciana, Valencia.

Framis, Maite (2006): "Los Cabanes", en De pintura valenciana (1400-1600), Alicante, Juan Gil-Albert, pp. 149-210.

García Cárcel, Ricardo (1973): "Las Germanías de Valencia y la actitud revolucionaria de los gremios", en Estudis, n. ${ }^{\circ} 2$, pp. 97-154.

García Cárcel, Ricardo (1975): Las Germanías de Valencia, Barcelona: Península.

77 En la fecha de octubre de 1527 se cita como ya fallecido pero carecemos de noticias exactas de las fecha de fallecimiento de Miguel Esteve, ya que como en el caso de Miguel del Prado, las últimas noticias documentadas sobre este pintor, son también de la Germanía de 1521. 
Gómez-Ferrer, Mercedes (2003): "La capilla del rosario en el convento de Santo Domingo", en Una arquitectura gótica mediterránea, II, Valencia: Generalitat Valenciana, pp. 193-197.

Gómez-Ferrer, Mercedes (2010): "Pintores aragoneses y navarros en Valencia (c.1490-1550)"; en Artigrama, pp. $345-$ 361.

Gómez-Ferrer, Mercedes (2011-12): "Los Falcó. Una familia de pintores en la Valencia del siglo XVI". En: Locus Amoenus, n. ${ }^{\circ} 11$, pp. $79-96$.

Gómez-Ferrer, Mercedes/Corbalán de Celis, Juan (2004): "La casa del obispo de Tortosa, Alfonso de Aragón. Un palacio valenciano en la encrucijada entre dos siglos (XV-XVI)", en Ars Longa, n. ${ }^{\circ} 13$, Valencia, pp. 11-31.

Gómez-Ferrer, Mercedes/Corbalán de Celis, Juan (2006): "Un contrato de los Hernandos para la capilla de les Febres de la Seo de Xàtiva en 1511”. En: Archivo de Español de Arte, pp. 157-168.

Gómez-Ferrer, Mercedes/Corbalán de Celis, Juan (2014): “El Pintor valenciano Franci Joan (act. 1481-1515), identificado como el anónimo maestro de San Narciso". En: Ars Longa, n. ${ }^{\circ 23}$, pp. 75-92.

Gómez Frechina, Jose (2011): Los Hernandos. Madrid: Arco/Libros.

Gómez Frechina, José (2012): El Maestro de Perea. Revisión historiográfica y análisis del corpus pictórico, Trabajo Fin de Master en Historia y Cultura Visual, defendido en el departamento de Historia del Arte, Universitat de València, el 4 de diciembre de 2012, inédita

Gómez Frechina, José (2014): http://www.levante-emv.com/cultura/2014/04/16/identificada-tabla-renacentista-valencia$\mathrm{na} / 1101593 . \mathrm{html}[12-12-15]$.

Gómez Frechina, José (2016): A new Christ carrying the cross by Sebastiano del Piombo. The Venetian Painter's legacy in Spain. Londres: Colnaghi.

López, María José/Samper, Vicente (2006): “Sobre pintores en el Reino de Valencia hacia la primera mitad del siglo XVI: aportación documental”, en De pintura valenciana (1400-1600), Alicante, Juan Gil-Albert, pp. 133-148.

Marco, Víctor (2013): "La Mare de Deu del Remei”, en Pulchra Magistri, La Luz de las imágenes, Valencia, Generalitat Valenciana, pp. 482-485.

Martínez Rondan, Josep (1998): El retaule de la Resurrecció de la Seu de València, Sagunt: J. Martínez.

Momblanch, Francisco (1966): "El obispo inquisidor Fray Juan Enguera y el retablo vicentino del maestro del Grifo", en Anales del centro de Cultura Valenciano, n. ${ }^{\circ} 51$, pp. 89-123.

Post, Chandler Rathfon (1953): The Valencian School in the Early Renaissance (A History of Spanish Painting, t. XI), Cambridge (Mass).

Salas, Xavier de (1943): "Escultores renacientes en el Levante español”, en Anales y Boletín de los Museos de Arte de Barcelona, Barcelona, pp. 35-87.

Samper, Vicente (1998): “Un Santiago Apóstol del 'Maestro del Grifo' en el Museo Lázaro Galdiano”, en Goya. núms. 265-266, pp. 274-276.

Samper, Vicente (2013): “La única primera aparición del Prado. Reivindicando una obra de Yáñez”, en Ars Longa, n. ${ }^{222,}$ pp. 99-109.

Samper, Vicente (2015): Miguel Esteve (h.1485-1527) y algunas consideraciones más sobre la pintura valenciana de su época, Tesis Doctoral, Universitat de València.

Sanchis Sivera, José (1930-31): "Pintores medievales en Valencia", en Archivo de Arte Valenciano, pp. 3-116.

Saralegui, Leandro de (1944): "Para el estudio de dos tablas italianas y varias españolas", en Boletín de la sociedad española de excursiones, Madrid, tomo 68, 1 trimestre, pp. 23-37.

Saralegui, Leandro de (1945): "Para el estudio de algunas tablas españolas", en Archivo Español de Arte, Tomo 18, n. ${ }^{\circ} 67$, pp. 17-32.

Saralegui, Leandro de (1954): El Museo Provincial de Bellas Artes de San Carlos. Tablas de las Salas 1. ${ }^{a}$ 2 ${ }^{a}{ }^{a}$ de primitivos valencianos, Institución Alfonso el Magnánimo, Valencia.

Saralegui, Leandro de (1955): "Miscelánea de tablas inéditas", en Archivo español de Arte, pp. 323-338.

Soler d'Hyver, Carlos (1999): "San Dimas y el donante", en La luz de las imágenes, Valencia, Generalitat Valenciana, pp. 438-439.

Soria, Jeronim [1559] (1960): Dietari, Valencia: Acción Bibliográfica Valenciana.

Teixidor, José [1755] (1949): Capillas y sepulturas del Real convento de predicadores de Valencia. Valencia: Acción Bibliográfica Valenciana.

Tormo, Elías (1932): Los Museos. Guías - Catálogo: Valencia, Madrid, vol. 1, p. 19.

Tramoyeres, Luis (1919): "La capilla de los Jurados de Valencia", en Archivo de Arte Valenciano, pp. 73-100.

Viciana, Martín de [1566] (2005): Crónica de la ínclita y coronada ciudad de Valencia y de su reino, libro IV. Valencia: Universitat de València.

Fecha de recepción: 14-I-2016

Fecha de aceptación: $19-\mathrm{V}-2016$ 